Research Article

\title{
Development of the Multiple Gene Knockout System with One-Step PCR in Thermoacidophilic Crenarchaeon Sulfolobus acidocaldarius
}

\author{
Shoji Suzuki and Norio Kurosawa \\ Department of Science and Engineering for Sustainable Development, Faculty of Science and Engineering, Soka University, \\ 1-236 Tangi-machi, Hachioji, Tokyo 192-8577, Japan
}

Correspondence should be addressed to Norio Kurosawa; kurosawa@soka.ac.jp

Received 30 June 2017; Revised 18 September 2017; Accepted 25 September 2017; Published 31 October 2017

Academic Editor: Sonja-Verena Albers

Copyright (c) 2017 Shoji Suzuki and Norio Kurosawa. This is an open access article distributed under the Creative Commons Attribution License, which permits unrestricted use, distribution, and reproduction in any medium, provided the original work is properly cited.

\begin{abstract}
Multiple gene knockout systems developed in the thermoacidophilic crenarchaeon Sulfolobus acidocaldarius are powerful genetic tools. However, plasmid construction typically requires several steps. Alternatively, PCR tailing for high-throughput gene disruption was also developed in S. acidocaldarius, but repeated gene knockout based on PCR tailing has been limited due to lack of a genetic marker system. In this study, we demonstrated efficient homologous recombination frequency $\left(2.8 \times 10^{4} \pm 6.9 \times 10^{3}\right.$ colonies/ $\mu \mathrm{g}$ DNA) by optimizing the transformation conditions. This optimized protocol allowed to develop reliable gene knockout via double crossover using short homologous arms and to establish the multiple gene knockout system with one-step PCR (MONSTER). In the MONSTER, a multiple gene knockout cassette was simply and rapidly constructed by one-step PCR without plasmid construction, and the PCR product can be immediately used for target gene deletion. As an example of the applications of this strategy, we successfully made a DNA photolyase- (phr-) and arginine decarboxylase- (argD-) deficient strain of $S$. acidocaldarius. In addition, an agmatine selection system consisting of an agmatineauxotrophic strain and $\operatorname{argD}$ marker was also established. The MONSTER provides an alternative strategy that enables the very simple construction of multiple gene knockout cassettes for genetic studies in S. acidocaldarius.
\end{abstract}

\section{Introduction}

High-throughput PCR tailing for gene disruption has been developed in the thermoacidophilic crenarchaeon Sulfolobus acidocaldarius [1]. We attempted to improve this technique and develop an efficient multiple gene knockout strategy with a PCR tailing (one-step PCR) method.

Gene knockout via homologous recombination is a powerful tool for the generation of specific mutants and subsequent functional analysis of the gene. Three unmarked gene deletion methodologies, that is, plasmid integration and segregation (PIS), marker replacement and looping out (MRL), and marker insertion and unmarked target gene deletion (MID), have been employed in S. acidocaldarius and S. islandicus [2-4]. These pop-out recombination-based approaches are effective for multiple gene knockout [5-7], but plasmid construction is required. In contrast, one-step PCR followed by a marker replacement system using the pyrE selection marker flanked by $40-50 \mathrm{bp}$ of homologous regions, for example, $5^{\prime}$ and $3^{\prime}$ flanking regions of the target gene, has been developed in S. acidocaldarius [1]. This PCR-tailing method allows for effective, high-throughput gene functional analysis without plasmid construction [1]. However, this method was not sufficient for repeated gene disruptions 
TABLE 1: Strains and DNA used in this study.

\begin{tabular}{|c|c|c|}
\hline Strain or plasmids & Relevant characteristic(s) & Source or reference \\
\hline \multicolumn{3}{|l|}{ Strains } \\
\hline \multicolumn{3}{|l|}{ S. acidocaldarius } \\
\hline SK-1 & MR31 [32] with $\Delta$ suaI & [8] \\
\hline DP-1 Int & SK-1 with $\Delta p h r: 3^{\prime}$ region of $p h r-p y r E-l a c S$ & This study \\
\hline DP-1 & SK-1 with $\Delta p h r$ & This study \\
\hline SK-5 Int & SK-1 with $\Delta \operatorname{argD}:: 5^{\prime}$ region of $\operatorname{argD}$-pyrE-lacS & This study \\
\hline SK-5 & SK-1 with $\triangle \arg D$ & This study \\
\hline \multicolumn{3}{|l|}{ Plasmids } \\
\hline pSAV2 & $\begin{array}{l}\text { Sulfolobus-E. coli shuttle vector, based on pBluescript II KS (-) and pRN1, } \\
\text { with the SsopyrEF marker }\end{array}$ & {$[8]$} \\
\hline pSAV2-argD & SsopyrEF marker in pSAV2 replaced by SsoargD marker & This study \\
\hline pSuaIPOP & $\begin{array}{l}\text { pBluescript II KS (-) carrying the } 800 \text { bp of } 5^{\prime} \text { and } 3^{\prime} \text { regions of suaI, pyrE, and } \\
800 \text { bp of } 3^{\prime} \text { region of suaI }\end{array}$ & {$[8]$} \\
\hline placSpyrE & $\begin{array}{l}\text { pSuaIPOP derivative carrying } 800 \mathrm{bp} \text { of } 5^{\prime} \text { and } 3^{\prime} \text { homologous regions of suaI locus } \\
\text { at both ends of pyrE-lacS dual marker }\end{array}$ & This study \\
\hline \multicolumn{3}{|c|}{ 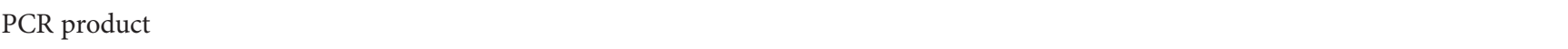 } \\
\hline pyrElacS800 & $\begin{array}{c}\text { Linear DNA carrying } 800 \text { bp of } 5^{\prime} \text { and } 3^{\prime} \text { homologous regions of sual locus at both } \\
\text { ends of pyrE-lacS dual marker }\end{array}$ & This study \\
\hline
\end{tabular}

because only the uracil selection system (pyrimidine-auxotrophic strain and selectable marker [ $p y r E]$ gene) was available in $S$. acidocaldarius. A pop-out recombination system using one-step PCR for multiple gene knockout has not been reported in hyperthermophilic archaea. Furthermore, the homologous recombination efficiency using the PCR-tailing technique has not been reported [1].

We recently constructed the restriction endonuclease SuaI-deficient S. acidocaldarius strain SK-1 (DpyrE $\Delta$ suaI), which has the potential for efficient and flexible direct modification of the genome using synthetic oligonucleotides or PCR products without any methylation procedures [8]. In our current study, we estimated the effects of transformation conditions (plating methods, DNA topology, $\mathrm{CaCl}_{2}$ treatment, recovery buffer, growth phase of cells, DNA volume, and flanking region length) on homologous recombination efficiency and optimized the transformation protocol for PCR tailing. If a combination system consisting of one-step PCR and pop-out excision is developed, alternative multiple gene knockout systems become accessible. To this end, pyrE-lacS dual marker genes were utilized for positive, negative, and blue selection. This effective approach (multiple gene knockout system with one-step PCR) was validated by unmarked gene knockout of the DNA photolyaseand arginine decarboxylase-encoding genes ( $p h r$ and $\operatorname{argD}$, resp.) in the SuaI-deficient S. acidocaldarius strain SK-1 $(\Delta$ pyrE $\Delta$ suaI).

\section{Materials and Methods}

2.1. Strains and Growth Conditions. The strains used in this study are listed in Table 1 . The $S$. acidocaldarius pyrimidine-auxotrophic and restriction endonuclease SuaIdeficient strain SK-1 ( $\operatorname{pyrE} \Delta s u a I)$ was used as basic host strain [8]. This strain and its derivatives were cultivated in xyrose and tryptone (XT) medium (pH3) [9] containing $1 \times$ basal salts $\left(3 \mathrm{~g} \mathrm{~K}_{2} \mathrm{SO}_{4}, 2 \mathrm{~g} \mathrm{NaH} \mathrm{PO}_{4}, 0.3 \mathrm{~g} \mathrm{MgSO}_{4} \cdot 7\right.$ $\mathrm{H}_{2} \mathrm{O}$, and $\left.0.1 \mathrm{~g} \mathrm{CaCl}_{2} \cdot 2 \mathrm{H}_{2} \mathrm{O}\right), 20 \mu \mathrm{L}$ of trace mineral solution $\left(1 \mathrm{mg} \mathrm{FeCl} \cdot 6 \mathrm{H}_{2} \mathrm{O}, 0.1 \mathrm{mg} \mathrm{CuCl}{ }_{2} \cdot 2 \mathrm{H}_{2} \mathrm{O}, 0.12 \mathrm{mg} \mathrm{CoSO} \cdot \cdot 7\right.$ $\mathrm{H}_{2} \mathrm{O}, 0.1 \mathrm{mg} \mathrm{MnCl}_{2} \cdot 4 \mathrm{H}_{2} \mathrm{O}$, and $0.1 \mathrm{mg} \mathrm{ZnCl}_{2}$ ), $2 \mathrm{~g} / \mathrm{L}$ xyrose, and $1 \mathrm{~g} / \mathrm{L}$ tryptone in $1 \mathrm{~L}$ Milli-Q $\mathrm{H}_{2} \mathrm{O}$ at $75^{\circ} \mathrm{C}$ with or without shaking $(160 \mathrm{rpm})$. To solidify plates, identical components of $1 \times$ basal salts containing $2.9 \mathrm{~g} \mathrm{MgSO}_{4} \cdot 7 \mathrm{H}_{2} \mathrm{O}$ and $0.5 \mathrm{~g} \mathrm{CaCl}_{2} \cdot 2 \mathrm{H}_{2} \mathrm{O}$ were used. For growth of the uracilauxotrophic strain, $0.02 \mathrm{~g} / \mathrm{L}$ uracil was added to XT medium (XTU). XTU medium supplemented with $50 \mu \mathrm{g} / \mathrm{mL} 5$-FOA was used for counterselection with the pop-out recombination method. For cultivation of the $\operatorname{argD}$ mutant, $1 \mathrm{mg} / \mathrm{mL}$ agmatine (agmatine sulfate [Tokyo Chemical Industry]) was added to the XTU medium. Escherichia coli strain $\mathrm{DH} 5 \alpha$, used for general manipulation, was routinely cultivated at $37^{\circ} \mathrm{C}$ in Luria-Bertani medium supplemented with ampicillin $(100 \mu \mathrm{g} / \mathrm{mL})$.

2.2. General DNA Manipulation. The reagents used in these experiments were prepared as previously described [8]. PCR products and plasmid DNA were purified using NucleoSpin Gel and PCR Clean-up and NucleoSpin QuickPure kits (Macherey-Nagel), respectively.

2.3. Construction of Marker Cassettes. The plasmid and linear DNA used in this study are shown in Table 1 and the PCR primers used are listed in Table 2.

2.3.1. Construction of Marker Cassettes for Estimation of Homologous Recombination Efficiency. We constructed the plasmid placSpyrE, which contains marker cassettes of approximately $800 \mathrm{bp}$ of the $5^{\prime}$ and $3^{\prime}$ homologous regions 
TABle 2: Primers used in this study.

\begin{tabular}{|c|c|}
\hline Primer & Sequence $^{\mathrm{a}}\left(5^{\prime}-3^{\prime}\right)$ \\
\hline SSOlacS-F & TTTCTGCAGTGTTTTTCTCTATATCAATCTC \\
\hline SSOlacS-R & TTTGGATCCATCTAAATGACTTTCCAATTAG \\
\hline E800-F & ACTTCTCСТССТTATTATAACG \\
\hline E800-R & GGATTCTCTTACTTTTCTAAAG \\
\hline E50-F & TGAGGGAAAAAATAAACGAAAAG \\
\hline E50-R & GACCTTGAATTTGAAGTGGC \\
\hline $\mathrm{E} 40-\mathrm{F}$ & AATAAACGAAAAGTTAGAAAAGAA \\
\hline E40-R & TTGAAGTGGCGTCTCTAGAT \\
\hline E30-F & AAGTTAGAAAAGAAATCTCAG \\
\hline E30-R & GTCTCTAGATCGTTAGCAC \\
\hline E20-F & AGAAATCTCAGTGACTGCAG \\
\hline E20-R & CGTTAGCACATAAAGTCAGTC \\
\hline E10-2F & ATCTCAGTGATGTTTTTCTCTATATCAATCTC \\
\hline E10-2R & TAAAGTCAGTACTCCTAGATCTAAAACTAAAG \\
\hline phr-pop-F & $\begin{array}{l}\text { ATGATGTTTTAGAACAAAAGATTATTTAGTTGTAGTATAATCATTAGTCCAAGGGGAAAAAGTA } \\
\text { TAAAGAGAAAACAATGTTTTTCTCTATATCAATCTC }\end{array}$ \\
\hline phr-pop-R & 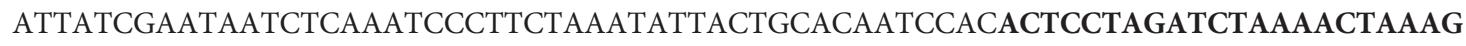 \\
\hline phr-out-F & AACGCTGGGATGCTGATAAG \\
\hline phr-out-R & ATGACCAGACTACTAACGTAC \\
\hline argD-pop-F & AAACCTAAACGTCATCAAATGTTTTTCGCAGATAGAAGTTCAGAGTGATGTTTTTCTCTATATCAATCTC \\
\hline argD-pop-R & $\begin{array}{c}\text { AATAGGTAGATGATGAAATTAAAAAAAGAGA } \\
\text { TCGATGATCAACTCAGCCTCCTTTTCTATTACCCTCCATCACCACTTACTCCTAGATCTAAAACTAAAG }\end{array}$ \\
\hline $\operatorname{argD-F-F}$ & TTACTTTATATATCTCATTCTG \\
\hline $\operatorname{argD-F-R~}$ & CTAATTAGGGAAATTGGTTAC \\
\hline SsoargD-KpnI-F & TTTGGTACCCTTATTACCTAGATATAACGTT \\
\hline SsoargD-PstI-R & TTTGTCGACTACTGCTTTGATCAAATATAAG \\
\hline
\end{tabular}

${ }^{a}$ Restriction sites are underlined and sequences of MONSTER primers that anneal with the pyrE-lacS marker genes are in bold.

of the suaI (Saci_1976) locus at both ends of the pyrE-lacS marker. The lacS gene, together with its putative promoter and terminator regions, was amplified from the $S$. solfataricus P2 genomic DNA using primers SSOlacS-F/R (containing PstI/BamHI restriction sites). The PCR product was digested with PstI/BamHI, then purified and inserted into pSuaIPOP [8] at the corresponding restriction sites. Linear DNA of the pyrE-lacS dual marker cassette containing various lengths $(800,50,40,30,20$, and $10 \mathrm{bp})$ of the $5^{\prime}$ and $3^{\prime}$ homologous arms was amplified from placSpyrE as a template using the corresponding primers (E800-20-F/R and E10-2F/2R) and Emerald Amp MAX PCR Master mix (Takara Bio). The PCR products were purified in $5 \mathrm{mM}$ Tris- $\mathrm{HCl}(\mathrm{pH} 8.5)$ and transformed into SK-1 to estimate the homologous recombination efficiency via double crossover (Figure 1).

2.3.2. Construction of phr and argD Knockout PCR Products. A MID strategy [3] and PCR-tailing technique [1] were combined to develop our multiple gene knockout system with one-step PCR (MONSTER). The MONSTER was utilized for phr (Saci_1227) and argD (Saci_1363) knockout cassette construction. In brief, the phr knockout PCR product (MONSTER-phr) was amplified from placSpyrE as a template using primers phr-pop-F/R (containing the $48 \mathrm{bp}$ and
$30 \mathrm{bp} 5^{\prime}$ and $3^{\prime}$ flanking regions of phr and a $48 \mathrm{bp}$ region of phr as the Tg-arm) and Premix Taq (Ex Taq Version 2.0; Takara Bio) under the following conditions: $94^{\circ} \mathrm{C}$ for $3 \mathrm{~min}$; 30 cycles of $94^{\circ} \mathrm{C}$ for $30 \mathrm{~s}, 56^{\circ} \mathrm{C}$ for $30 \mathrm{~s}$, and $72^{\circ} \mathrm{C}$ for $3 \mathrm{~min}$, and a final extension for $3 \mathrm{~min}$. Similarly, the $\operatorname{argD}$ knockout PCR product (MONSTER-argD) was amplified from placSpyrE as a template using primers argD-pop-F/R (containing a $48 \mathrm{bp}$ region of $\operatorname{argD}$ as the Tg-arm and the $30 \mathrm{bp}$ and $48 \mathrm{bp}$ $5^{\prime}$ and $3^{\prime}$ flanking regions of $\operatorname{argD}$ ) and the LA-Taq DNA polymerase (Takara Bio) under same PCR conditions. The purified PCR products were used in subsequent experiments.

2.3.3. Construction of an argD-Based Shuttle Vector. The S. solfataricus $\operatorname{argD}$ gene with approximately $100 \mathrm{bp}$ of the $5^{\prime}$ and $3^{\prime}$ flanking regions was amplified by PCR using the primers SsoargD-KpnI-F/PstI-R, which contain the KpnI and PstI restriction sites, respectively, and Premix Taq (Ex Taq Version 2.0; Takara Bio). The SsopyrEF marker genes in pSAV2 [8] were replaced by the SsoargD marker gene at the KpnI and PstI sites, thus generating the $\operatorname{argD}$-based shuttle vector pSAV2-argD.

2.4. Transformation Procedure. Preparation of electrocompetent cells and transformation were completed as previously 


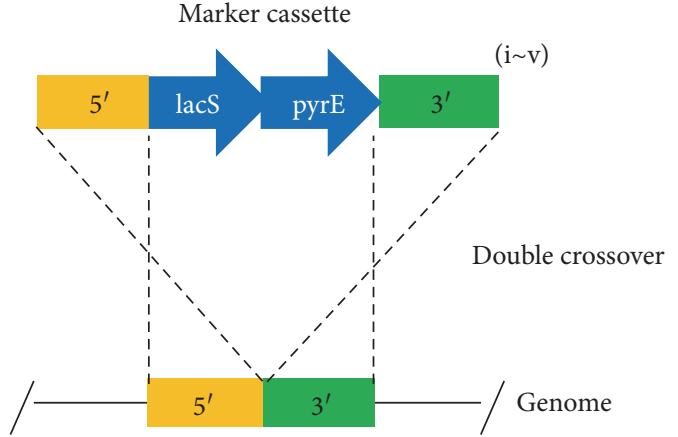

(vi \& vii)

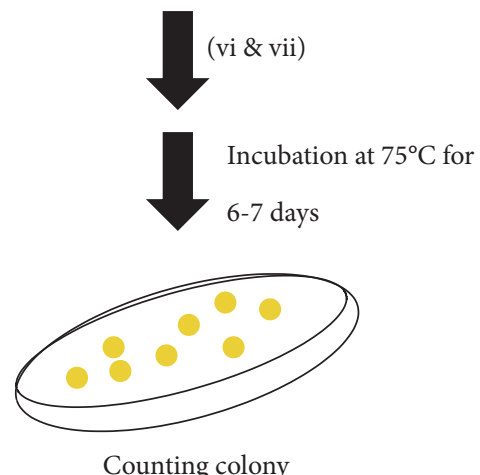

Figure 1: Schematic and optimization of transformation procedure. A marker cassette containing the $5^{\prime}$ and $3^{\prime}$ homologous regions of the target locus at both ends of pyrE-lacS marker genes was electroporated into strain SK-1 ( $\triangle p y r E \Delta s u a I)$ under various conditions: (i) DNA topology, (ii) $\mathrm{CaCl}_{2}$ treatment, (iii) growth phase of competent cells, (iv) DNA volume, and (v) length of flanking region. After electroporation, cells were cultivated in recovery buffer (vi) as needed and plated onto XT plates by spreading or overlay plating (vii). The resulting colonies were defined as transformants and counted.

described [8] with the following modifications. Cells were incubated in a $1 \mathrm{~L}$ DURAN bottle (Schott) containing $200 \mathrm{~mL}$ of medium with shaking using a Bio shaker (TAITEC). S. acidocaldarius (strain SK-1 [ $\Delta$ pyrE $\Delta$ suaI]) electrocompetent cells for transformation with a shuttle vector and via homologous recombination were prepared from a late $\log$ to stationary phase culture $\left(\mathrm{OD}_{600} \geqq 0.7\right)$ and an early to midlog phase culture $\left(\mathrm{OD}_{600}=0.1-0.4\right)$ incubated in XTU medium, respectively. Cells were harvested by centrifugation $\left(10160 \times \mathrm{g}\right.$ for $15 \mathrm{~min}$ at $\left.25^{\circ} \mathrm{C}\right)$ using a Kubota 6500 and were washed once in 0.3 volumes of the original culture volume of $20 \mathrm{mM}$ sucrose at room temperature. The final optical density at $600 \mathrm{~nm}\left(\mathrm{OD}_{600}\right)$ of cells was adjusted to $5.9\left(2 \times 10^{9}\right.$ cells $/ \mathrm{mL}$ ) by calculation, and aliquots were frozen at $-84^{\circ} \mathrm{C}$ in an ultralow freezer (Sanyo). All transformation procedures (including preparation of competent cells) were carried out at room temperature. Two hundred microliters of competent cells $\left(4 \times 10^{8}\right.$ cells $)$ were thawed by hand and mixed with $1-10 \mu \mathrm{L}$ of DNA in $5 \mathrm{mM}$ Tris- $\mathrm{HCl}$ (pH 8.5). For the $\mathrm{CaCl}_{2}$ treatment, $40 \mathrm{mM} \mathrm{CaCl}_{2}$ was added to cells at a final concentration of $0.1-0.4 \mathrm{mM} \mathrm{CaCl}_{2}$. After pipetting or vortexing, approximately $200 \mu \mathrm{L}$ of the competent cell-DNA mixture was transferred to a $2 \mathrm{~mm}$ electroporation cuvette (Bio-Rad or NeppaGene). Electroporation was performed using the Gene Pulser II (Bio-Rad) set to a 2.5 or $3.0 \mathrm{kV}$ exponential decay pulse form for 9 or $20 \mathrm{~ms}$, respectively. After electroporation, regeneration was performed as needed. Sulfolobus cells were immediately transferred into $800 \mu \mathrm{L}$ of recovery buffer consisting of $20 \mathrm{mM}$ sucrose; $2 \times$ basal 4 (modified $2 \times$ basal salts with $5.75 \mathrm{~g} \mathrm{MgSO}_{4} \cdot 7 \mathrm{H}_{2} \mathrm{O}$ and $1 \mathrm{~g} \mathrm{CaCl}_{2} \cdot 2 \mathrm{H}_{2} \mathrm{O}$, $40 \mu \mathrm{L}$ of trace mineral solution, and $50 \mu \mathrm{L}$ of $50 \% \mathrm{H}_{2} \mathrm{SO}_{4}$ in $1 \mathrm{~L}$ of Milli-Q $\mathrm{H}_{2} \mathrm{O}$ ); a previously described incubation solution $\left(0.3 \%\left(\mathrm{NH}_{4}\right)_{2} \mathrm{SO}_{4}, 0.05 \% \mathrm{~K}_{2} \mathrm{SO}_{4}, 0.01 \% \mathrm{KCl}\right.$, and $0.07 \%$ glycine, $\mathrm{pH} 4.7$ ) [10] with a modified $\mathrm{pH}$ (named Buffer $\mathrm{C}$ in this study); and modified Brock's basal salt mixture (MBS), pH $4.7\left(1.3 \mathrm{~g}\left(\mathrm{NH}_{4}\right)_{2} \mathrm{SO}_{4}, 0.2 \mathrm{~g} \mathrm{KH}_{2} \mathrm{PO}_{4}, 0.25 \mathrm{~g}\right.$ $\mathrm{MgSO}_{4} \cdot 7 \mathrm{H}_{2} \mathrm{O}, 0.07 \mathrm{~g} \mathrm{CaCl}_{2} \cdot 2 \mathrm{H}_{2} \mathrm{O}, 2.0 \mathrm{mg} \mathrm{FeCl} \cdot 6 \mathrm{H}_{2} \mathrm{O}$, $1.8 \mathrm{mg} \mathrm{MnCl} \cdot 4 \mathrm{H}_{2} \mathrm{O}, 4.5 \mathrm{mg} \mathrm{Na}_{2} \mathrm{~B}_{4} \mathrm{O}_{7} \cdot 10 \mathrm{H}_{2} \mathrm{O}, 0.22 \mathrm{mg}$ $\mathrm{ZnSO}_{4} \cdot 7 \mathrm{H}_{2} \mathrm{O}, 0.05 \mathrm{mg} \mathrm{CuCl} \cdot 2 \mathrm{H}_{2} \mathrm{O}, 0.03 \mathrm{mg} \mathrm{Na} \mathrm{MoO}_{4} \cdot 2$ $\mathrm{H}_{2} \mathrm{O}, 0.03 \mathrm{mg} \mathrm{VOSO}_{4} \cdot 2 \mathrm{H}_{2} \mathrm{O}$, and $0.01 \mathrm{mg} \mathrm{CoSO} \mathrm{C}_{4} \cdot 7 \mathrm{H}_{2} \mathrm{O}$ in $1 \mathrm{~L}$ of Milli-Q $\mathrm{H}_{2} \mathrm{O}$ ) [11]. Cells were then incubated at $77^{\circ} \mathrm{C}-78^{\circ} \mathrm{C}$ for $30 \mathrm{~min}$ without shaking in a hot block (TOHO). After the regenerated samples were centrifuged $\left(11000 \times \mathrm{g}\right.$ for $1 \mathrm{~min}$ at $\left.25^{\circ} \mathrm{C}\right), 800 \mu \mathrm{L}$ of supernatant was removed and the pellet was suspended in $200 \mu \mathrm{L}$ followed by spreading on plates. Two plating methods, that is, direct plating and overlay cultivation, were performed. For direct plating, the transformed cells were immediately spread onto XT plates and incubated at $75^{\circ} \mathrm{C}$ for 6-7 days in sealed plastic cases. For overlay cultivation, transformed cells $(\sim 1 \mathrm{~mL})$ were mixed with $10 \mathrm{~mL}$ of prewarmed top gel solution $(5 \mathrm{~mL}$ of XT medium, $5 \mathrm{~mL}$ of $0.4 \%$ gellan gum, $50 \mu \mathrm{L}$ of $0.5 \mathrm{M} \mathrm{CaCl}_{2}$, and $50 \mu \mathrm{L}$ of $2 \mathrm{M} \mathrm{MgSO}_{4}$ ) at $75^{\circ} \mathrm{C}$, then poured onto XT plates and cultivated at $75^{\circ} \mathrm{C}$ for 6-7 days in sealed plastic cases.

2.5. X-Gal Assay. $\beta$-Glycosidase activity encoded by the lacS gene was detected in transformant colonies by spraying a $10 \mathrm{mg} / \mathrm{mL}$ X-gal (Wako or Carbosynth) solution on the plates and incubating at $75^{\circ} \mathrm{C}$ for 1 day. Transformants $\left(\right.$ lacS $\left.^{+}\right)$convert the chemical into a strong blue substance, whereas nontransformants (wild-type $S$. acidocaldarius) do not [12].

2.6. Estimation of Transformation Efficiency. When pyrE or $\arg D$ selectable marker was used for positive selection, colonies appearing on the plate were scored except for tiny colonies that might have been background.

2.7. Characterization of Mutant Strains. To characterize the phenotypes of the DNA photolyase-deficient strain DP-1 ( $\triangle$ pyrE $\Delta$ suaI $\Delta$ phr) and $\operatorname{argD}$ deletion mutant SK-5 ( $\Delta$ pyrE $\Delta$ suaI $\triangle \arg D)$, UV sensitivity and agmatine auxotrophy were examined, respectively.

To assess photoreactivation [1] in the strain DP-1, the growth properties under light and dark conditions after UV irradiation were examined. One milliliter of each overnight culture (late log to stationary phase) was poured in $90 \times 15 \mathrm{~mm}$ plastic petri dishes (IWAKI) and irradiated with a UV lamp (UVM-57) (304 nm, 6 W) (Tech-jam) positioned $6.5 \mathrm{~cm}$ from the top of the dish at room temperature for $60 \mathrm{~s}$ $\left(1200 \mathrm{~J} / \mathrm{m}^{2}\right)$. UV-irradiated cultures were immediately inoculated into $6 \mathrm{~mL}$ of XTU liquid medium to yield an initial 
$\mathrm{OD}_{600}$ of 0.005 . Cells were then cultivated with shaking. For mock-treated control cultures, the same procedure was followed without UV irradiation. For dark conditions, test tubes and Bio shakers (TAITEC) were covered in foil. For light conditions, cells were cultivated under a white LED using ODS-LS16-W (Ohm Electric). Cell growth was monitored thereafter.

To compare the growth properties of strain SK-5 in the presence or absence of agmatine, overnight cultures (late $\log$ to stationary phase) were inoculated into $6 \mathrm{~mL}$ of XTU liquid medium supplemented with $100-1000 \mu \mathrm{g} / \mathrm{mL}$ agmatine to yield an initial $\mathrm{OD}_{600}$ of 0.005 . Cells were cultivated with shaking and cell growth was monitored thereafter.

Transformant genotypes were analyzed by sequencing the target region following PCR amplification using primer sets that anneal outside the flanking target gene locus.

\section{Results}

3.1. Effects of Transformation Conditions on Homologous Recombination Efficiency. The PCR-tailing technique for gene disruption was developed in the thermoacidophilic crenarchaeon S. acidocaldarius [1]; however, transformation efficiency has not been reported. Homologous region length can significantly impact transformation efficiency [13]. The efficiency of homologous recombination via double crossover using very short homologous arms (50 10 bp) is likely very low. The widely used transformation procedure for Sulfolobus has been reported; however, the effects of transformation conditions on transformation efficiency have not been characterized in detail as compared to those of other model systems [14-16]. To develop a reliable multiple gene knockout system using PCR tailing, we first optimized the following transformation conditions: plating methods, DNA topology, $\mathrm{CaCl}_{2}$ treatment, recovery buffer, growth phase of cells, DNA volume, and length of flanking regions (Figure 1).

We examined the effects of two plating methods on transformation efficiency (Figure 1, vii). We used $200 \mathrm{ng}$ of linear DNA from pyrElacS800 (800 bp homologous arms Table 1), and competent cells were harvested at mid$\log$ phase culture $\left(\mathrm{OD}_{600}=0.391\right)$. After electroporation $(12.5 \mathrm{kV} / \mathrm{cm}, 20 \mathrm{~ms})$, the samples were immediately plated using two plating methods: direct plating or overlay cultivation. The transformation efficiency for direct plating was $7.5 \times 10^{2} \pm 2.2 \times 10^{2}$ colonies/ $\mu \mathrm{g}$ DNA, while that of overlay cultivation was $2.7 \times 10^{2} \pm 4.0 \times 10$ colonies $/ \mu$ g DNA. Thus, the transformation efficiency for direct plating was 2.7 -fold higher than that of overlay cultivation. The experiments were repeated in triplicate.

To analyze the effect of DNA topology on homologous recombination via double-crossover events, circular and linear marker cassettes containing 800 bp homologous regions were tested (Figure 1, i). The experimental conditions were identical to those described in the previous paragraph, except that $300 \mathrm{ng}$ of circular DNA pyrElacS800 (placSpyrE) and another previously reported electric parameter $(15 \mathrm{kV} / \mathrm{cm}$, $9 \mathrm{~ms}$ ) [17] were utilized. When DNA was electroporated, the transformation efficiency using linear DNA was 24 -fold higher than that of the circular DNA: $1.5 \times 10^{3} \pm 4.2 \times 10^{2}$

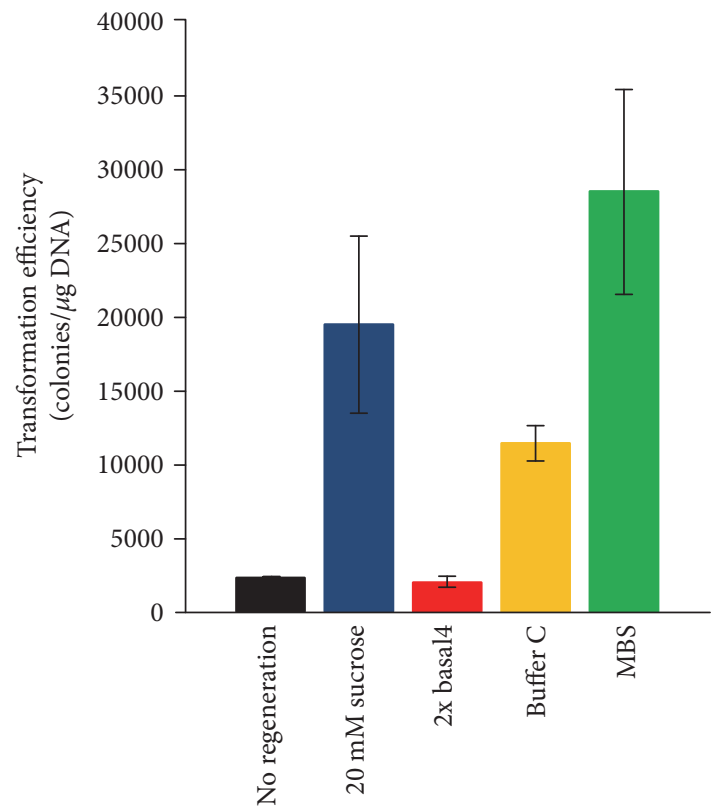

FIgURE 2: Effects of recovery conditions on transformation efficiency. SK-1 cells harvested at early to midlog phase $\left(\mathrm{OD}_{600}=0.308\right)$ were transformed with $200 \mathrm{ng}$ of pyrElacS800. After electroporation $(15 \mathrm{kV} / \mathrm{cm}, 9 \mathrm{~ms})$, the cell suspension was transferred to $800 \mu \mathrm{L}$ of recovery buffer $(20 \mathrm{mM}$ sucrose, $2 \times$ basal 4 , Buffer C, and MBS) and incubated. Ten percent of the regenerated sample was mixed with $10 \mathrm{~mL}$ of top gel solution and poured onto XT plates by overlay cultivation. Error bars represent the standard deviation of three independent experiments.

colonies $/ \mu \mathrm{g}$ DNA and $6.2 \times 10 \pm 7.0$ colonies $/ \mu \mathrm{g}$ DNA, respectively. The experiments were repeated in triplicate.

Electroporation in the presence of $\mathrm{Ca}^{2+}$ enhanced the transformation efficiency of E. coli [14]; however, this effect has not been reported in the hyperthermophilic genus Sulfolobus. For validation of the effect of $\mathrm{CaCl}_{2}$ treatment on homologous recombination efficiency in S. acidocaldarius, electrotransformation was performed in the presence and absence of $\mathrm{CaCl}_{2}$ (Figure 1, ii). Competent cells were collected at midlog phase $\left(\mathrm{OD}_{600}=0.420\right)$. Concentrations of $0.1,0.2$, and $0.4 \mathrm{mM} \mathrm{CaCl}_{2}$ were selected because these concentrations did not cause arching during electroporation. However, $\mathrm{CaCl}_{2}$ treatment did not improve transformation efficiency when compared with control experiments (data not shown). The experiments were repeated in triplicate. We speculated that DNA volume is important for improving transformation efficiency with $\mathrm{CaCl}_{2}$ treatment (Figure 1, iv). However, DNA volume (1000 ng) did not improve the transformation efficiency with $\mathrm{CaCl}_{2}$ treatment (data not shown).

We confirmed the effects of various regeneration conditions on transformation efficiency after electroporation (Figures 1, vi and 2) because our previous transformation protocol [8] did not conduct regeneration. The highest number of transformants was obtained with MBS buffer when compared with the control (without regeneration). The transformation efficiency was approximately 13 -fold higher than that of the control $\left(2.8 \times 10^{4} \pm 6.9 \times 10^{3}\right.$ colonies $/ \mu \mathrm{g}$ DNA and $2.3 \times 10^{3}$ colonies/ $\mu$ g DNA, resp.). The experiments were repeated in triplicate. 


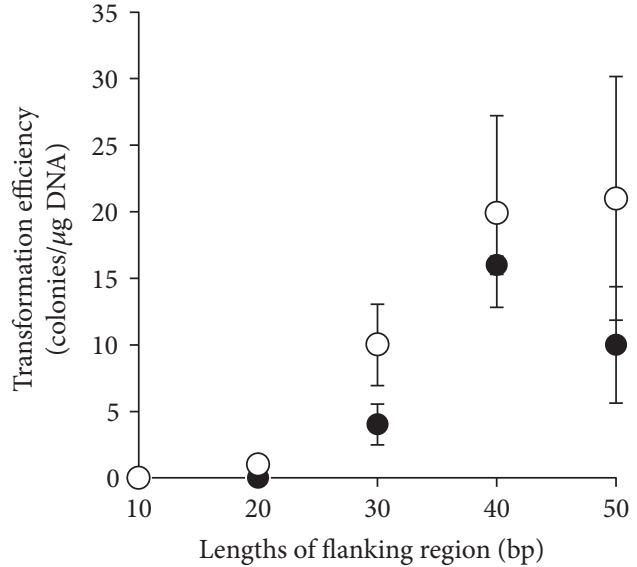

FIgURE 3: Effects of length of the flanking homologous region on transformation efficiency. SK-1 was transformed with $1 \mu \mathrm{g}$ of a linear marker cassette attached to flanking regions $(10-50 \mathrm{bp})$ of various lengths at both ends. The resulting colonies were counted. Open circles: regeneration in MBS; closed circles: direct plating (no regeneration). Error bars represent the standard deviation of three independent experiments.

Homologous recombination efficiencies for cells harvested at different phases of cell growth (early log $\left[\mathrm{OD}_{600}=0.174\right]$, midlog $\left[\mathrm{OD}_{600}=0.420\right]$, and stationary phase $\left[D_{600}=0.885\right]$ ) were investigated (Figure 1, iii). Competent cells were transformed with $200 \mathrm{ng}$ of pyrElacS800 by electroporation. Next, $20 \%$ suspensions were plated and cultivated. The transformation efficiency of fresh cultures was 2.6-4.5-fold higher than that of older cultures (midlog and stationary phases, resp.). The transformation efficiencies of early log, midlog, and stationary phases were $7.7 \times 10^{2} \pm 2.9 \times 10^{2}$ colonies/ $\mu \mathrm{g}$ DNA, $2.9 \times 10^{2} \pm 2.0 \times 10^{2}$ colonies $/ \mu \mathrm{g}$ DNA, and $1.7 \times 10^{2} \pm 3.8 \times 10$ colonies $/ \mu \mathrm{g}$ DNA, respectively. The experiments were repeated in triplicate.

Subsequently, to study the transformation efficiency using linear DNA for homologous recombination in S. acidocaldarius with double-crossover events, marker cassettes containing $50-10 \mathrm{bp} 5^{\prime}$ and $3^{\prime}$ homologous regions of the target locus at both ends of the pyrE-lacS marker were constructed (Figure 1, v). Competent cells harvested at midlog phase $\left(\mathrm{OD}_{600}=0.420\right)$ were transformed with $1 \mu \mathrm{g}$ of marker cassettes. The transformation efficiency increased with the length of the homologous arms (Figure 3). When DNA with $10-20 \mathrm{bp}$ of flanking regions was used, no transformants grew. Transformation efficiencies slightly improved by regeneration with MBS buffer. A few colonies transformed with DNA attached to $20 \mathrm{bp}$ flanking arms were detected after regeneration. Thus, efficient marker replacement was possible with as few as 30-50 bp of flanking homology of the target region.

The following set of conditions was established as the optimized transformation protocol: DNA was introduced into competent cells collected from the early log phase by electroporation. The pulse duration was $9 \mathrm{~ms}$ and the field strength was $15 \mathrm{kV} / \mathrm{cm}$. After electroporation, cells were regenerated in MBS recovery buffer and the pellet was spread on plates.
3.2. Establishment of the MONSTER. The multiple gene knockout system with one-step PCR (MONSTER) was developed by combining a MID strategy [3] and one-step inactivation using a linear PCR product [1] (Figures 4 and 5). Two $48 \mathrm{bp}$ homologous arms were used for double-crossover events (marker integration), followed by pop-out recombination at $30 \mathrm{bp}$ duplicated arms for the excision of a marker cassette (unmarked gene deletion). Thus, two MONSTER primers need to be designed for incorporation of $5^{\prime}, 3^{\prime}$, and $\mathrm{Tg}$ (target gene) arms into PCR products as $5^{\prime}$ extensions of primers (Table 2). Sequences of forward and reverse MONSTER primers that anneal with pyrE-lacS marker genes are identical although the attached flanking regions of target genes $\left(5^{\prime}, 3^{\prime}\right.$, and Tg) are different. Next, the MONSTER cassette was amplified by one-step PCR using MONSTER primers. Then, we designed different constructs of MONSTER cassettes (MONSTER-phr and MONSTER-argD) for confirming the reliability (Figures 4(a) and 5(a)). The dual marker (pyrE-lacS) was utilized for effective selection of correct transformants (Figures 4 and 5).

3.3. Construction of a DNA Photolyase-Deficient Strain via the MONSTER. To validate the MONSTER, we constructed a mutant with an in-frame deletion of DNA photolyase. DNA photolyase-encoding gene (Saci_1227) (named phr in this study) has been identified as a functional gene of photoreactivation (repair of UV-damaged DNA under light conditions) $[1,18]$. To disrupt phr, MONSTER-phr was constructed by one-step PCR (Figure 4(a)). When $1.6 \mu \mathrm{g}$ of MONSTER-phr was electroporated into SK-1 using the optimized transformation protocol with competent cells harvested at midlog phase $\left(\mathrm{OD}_{600}=0.420\right)$, approximately 60 colonies grew on XT plates (Figure 4(b)). Next, three blue colonies were selected after applying $1 \mu \mathrm{L}$ of X-gal solution $(10 \mathrm{mg} / \mathrm{mL})$ onto the plates for $1 \mathrm{~h}$ at $75^{\circ} \mathrm{C}$ (Figure $4(\mathrm{~b})$ ). Two blue colonies were purified by single isolation and analyzed by PCR screening using primers phr-out-F/R (Figure 4(a)). As shown in Figure 4(d), the two colonies were positive intermediate transformants (named DP-1 Int-1 and Int-2). A total of $2.3 \times 10^{8} \mathrm{DP}-1$ Int cells were spread on XTU plates containing 5-FOA for pop-out recombination. X-gal visualization of the plates indicated that blue and white colonies formed with a ratio of $100: 13$ (Figure 4(c), $65 \pm 35$ white colonies grew). Ten $5-\mathrm{FOA}^{\mathrm{r}}$ white colonies were randomly selected for PCR analysis. The genotypes of 9 out of ten colonies were expected with an approximate $1.3 \mathrm{~kb}$ deletion in the $p h r$ locus (Figure 4(d)). One correct $\Delta p h r$ in-frame mutant confirmed by sequencing was designated as $S$. acidocaldarius strain DP-1 and used for phenotypic analysis.

3.4. Characterization of the DNA Photolyase-Deficient Strain $D P-1$. To characterize the DNA photolyase-deficient strain, the growth properties of wild-type (SK-1) and $\Delta p h r$ (DP-1) under light or dark conditions after UV irradiation were investigated (Figure 6). When both strains were not irradiated with UV light, their growth properties were identical under light and dark conditions. In addition, the growth of UV-treated DP-1 under dark conditions was similar to that of the host strain. In contrast, the UV-exposed DNA 


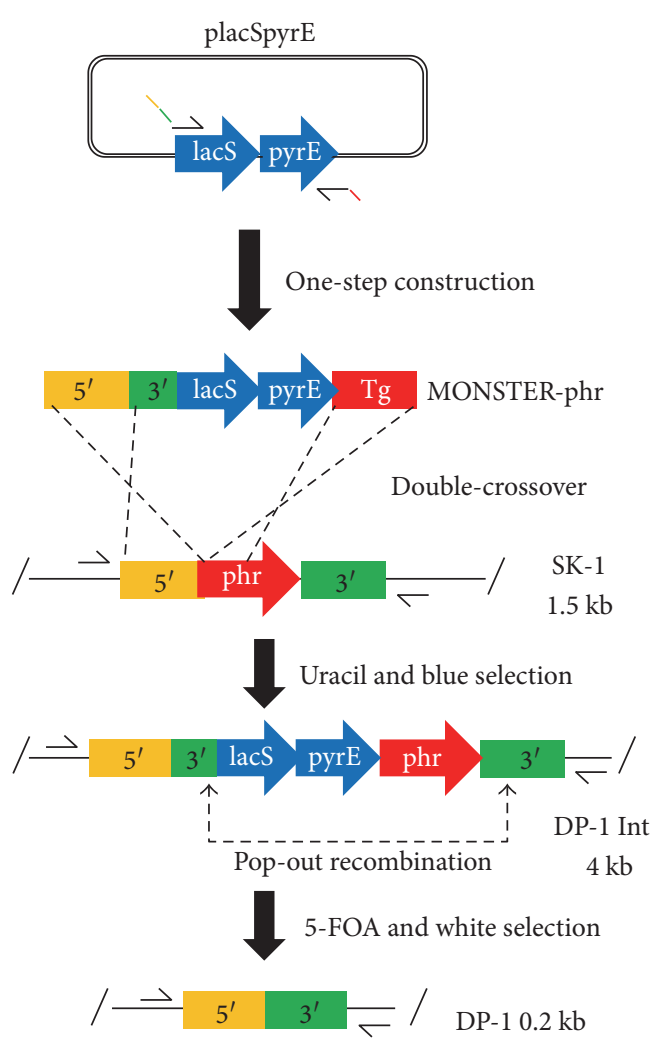

(a)

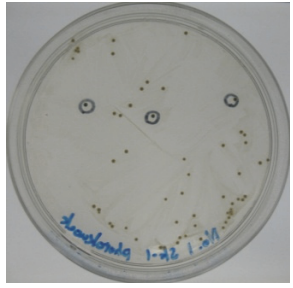

(b)

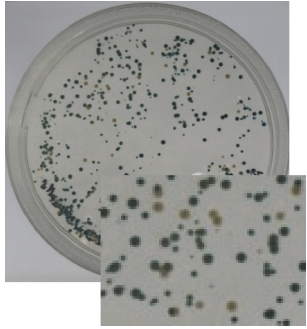

(c)

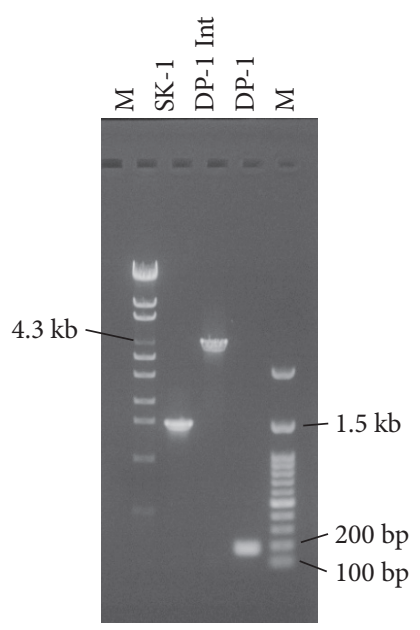

(d)

FIGURE 4: Schematic of the multiple gene knockout system with one-step PCR (MONSTER). (a) Construction of a DNA photolyase-encoding gene ( $p h r$ ) deletion mutant. A plasmid-borne pyrE-lacS marker served as the PCR template, which attached S. acidocaldarius chromosomal sequences $\left(5^{\prime}, 3^{\prime}\right.$, and partial sequences of $p h r$ at the $5^{\prime}$ ends of the primers) to the ends of the selectable dual marker. After one-step construction, the MONSTER-phr was electroporated into strain SK-1. A double crossover between the MONSTER-phr and the chromosome at the $5^{\prime}$ and $\mathrm{Tg}$ regions results in the pyrE-lacS marker and $3^{\prime}$ region insertion at the phr locus. The resulting uracil prototroph transformants that exhibit blue colonies can be selected on uracil-free plates. A DNA photolyase deletion mutant with the marker removed was generated by pop-out recombination at two duplicated $3^{\prime}$ regions, which can be selected by 5 -FOA counterselection in combination with X-gal staining. Arrows show the positions of PCR primer sets. (b) Uracil and blue selection plate. (c) 5-FOA and white selection plate. (d) PCR analysis of the phr locus of the S. acidocaldarius strains SK-1 ( $\Delta$ pyrE $\Delta s u a I)$, DP-1 Int (intermediate), and DP-1 ( $\Delta$ pyrE $\Delta$ suaI $\Delta p h r)$ using phr-out-F/R as primers. The expected sizes of the PCR bands were $1.5 \mathrm{~kb}$ (wt), $4 \mathrm{~kb}$ (recombinant), and $0.2 \mathrm{~kb}$ (deletion mutant). A $\lambda$-EcoT14 or $100 \mathrm{bp}$ DNA ladder was loaded in lane M.

photolyase-deficient strain DP-1 grew slower when compared with the SK-1 strain under light conditions, indicating that deletion of the phr locus eliminated photoreactivation.

3.5. Construction of the argD-Deficient S. acidocaldarius Strain SK-5 via the MONSTER. We disrupted the $\operatorname{argD}$ gene using the MONSTER to establish a robust unmarked gene disruption system, and a positive selectable marker in S. acidocaldarius (Figure 5). argD (Saci_1363) encodes arginine decarboxylase, which catalyzes ${ }_{L}$-arginine to produce agmatine [19], and is a homolog to SSO0536 in S. solfataricus P2 and SisM164_1585 in S. islandicus M.16.4, sharing 73\% and $74 \%$ identity by Blastp analysis, respectively. For construction of the $\arg D$ in-frame deletion mutant (Figure 5(a)), $2 \mu \mathrm{g}$ of one-step constructed MONSTER-argD was introduced into SK-1 cells harvested at the late-log phase $\left(\mathrm{OD}_{600}=0.558\right.$; electroporation conditions: $12.5 \mathrm{kV} / \mathrm{cm}$ and $20 \mathrm{~ms}$ ) and then cultivated on XT plates containing $200 \mu \mathrm{g} /$ $\mathrm{mL}$ agmatine at $75^{\circ} \mathrm{C}$ for 6 days. As shown in Figure 5(b), five colonies grew. X-gal selection revealed three blue colonies. Two of these blue colonies were purified on XT plates and analyzed by PCR screening using primers argD-F-F/R (Figure 5(a)). As shown in Figure 5(d), both clones contained $2.5 \mathrm{~kb}$ (pyrE-lacS marker and $30 \mathrm{bp} 5^{\prime}$ regions) inserted bands, indicating that two blue colonies were positive intermediate transformants (named SK-5 Int-1 and Int-2). These transformants grew in XT liquid culture, suggesting that insertion of the marker between the stop codon and the $3^{\prime}$ region of the $\arg D$ locus did not affect arginine decarboxylase activity (data not shown). A total of $3.4 \times 10^{8}$ SK-5 Int cells were spread on XTU plates containing 5-FOA and $1 \mathrm{mg} / \mathrm{mL}$ agmatine for pop-out recombination. X-gal visualization demonstrated that blue and white colonies formed with a ratio of $167: 16$ (Figure 5(c), 16 \pm 6 white colonies grew). Twelve 5-FOA ${ }^{\mathrm{r}}$ white colonies were randomly selected for PCR analysis using outer primers. The genotypes of 10 out of twelve colonies showed the expected approximately $0.4 \mathrm{~kb}$ deletion in the $\operatorname{argD}$ locus (Figure 5(d)). One correct 


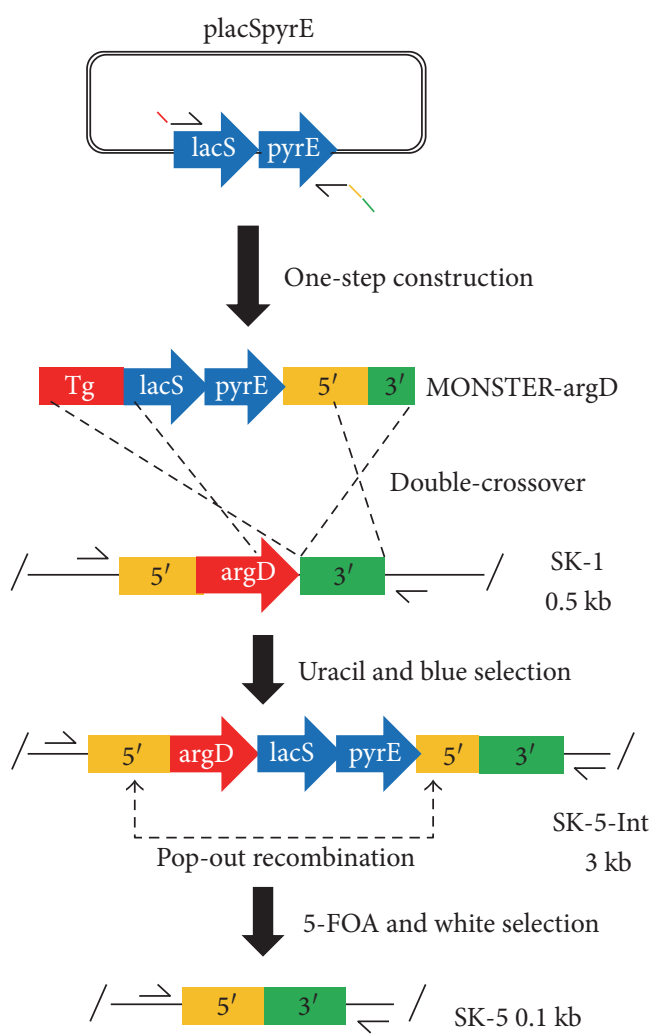

(a)

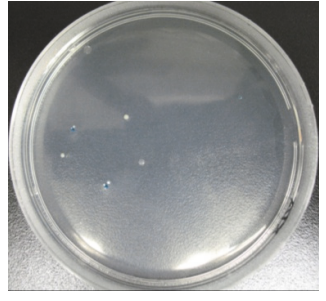

(b)

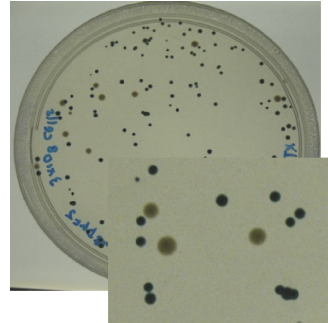

(c)

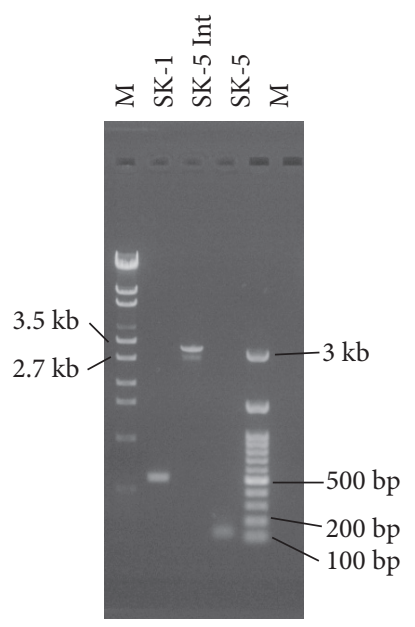

(d)

FIGURE 5: In-frame deletion of $\operatorname{argD}$ via the MONSTER. (a) Construction of an $\arg D$ deletion mutant. A plasmid-borne pyrE-lacS marker served as the PCR template, which attached S. acidocaldarius chromosomal sequences $\left(5^{\prime}, 3^{\prime}\right.$, and partial sequences of argD at the $5^{\prime}$ ends of the primers) to the ends of the selectable dual marker. After one-step construction, the MONSTER-argD was electroporated into strain SK-1. A double crossover between the MONSTER-argD and the chromosome at the Tg and $3^{\prime}$ regions results in the pyrE-lacS marker and $5^{\prime}$ region insertion at the $\operatorname{argD}$ locus. The resulting uracil prototroph transformants exhibit blue colonies and can be selected on uracil-free plates. An $\arg D$ deletion mutant with the marker removed was generated by pop-out recombination at two duplicated $5^{\prime}$ regions, which can be selected by 5-FOA counterselection in combination with X-gal staining. Arrows show the positions of PCR primer sets. (b) Uracil and blue selection plate. (c) 5-FOA and white selection plate. (d) PCR analysis of the $\operatorname{argD}$ locus of the S. acidocaldarius strains SK-1 ( $\Delta$ pyrE $\Delta$ suaI), SK-5 Int (intermediate), and SK-5 ( $\operatorname{ppyrE~} \Delta$ suaI $\Delta \operatorname{argD})$ using $\operatorname{argD-F-F/R}$ as primers. The expected sizes of the PCR bands were $0.5 \mathrm{~kb}$ (wt), $3 \mathrm{~kb}$ (recombinant), and $0.1 \mathrm{~kb}$ (deletion mutant). A $\lambda$-EcoT14 or $100 \mathrm{bp}$ DNA ladder was loaded in lane M.

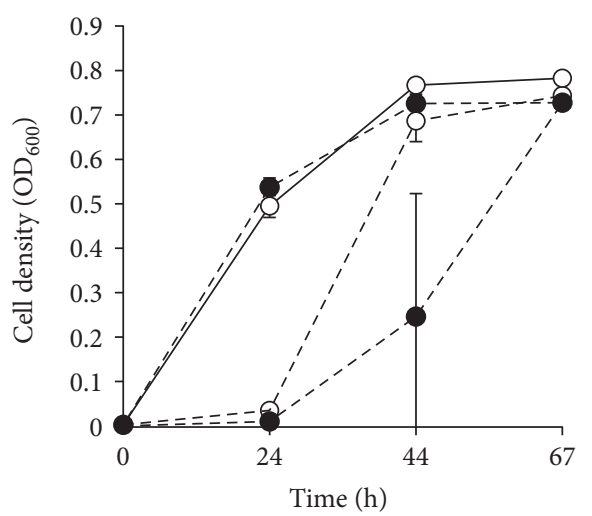

(a)

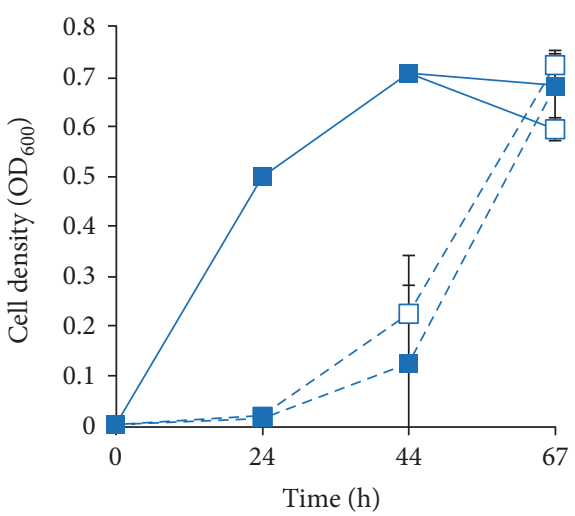

(b)

FIGURE 6: Growth curve of DNA photolyase-deficient strain after UV irradiation. Wt (SK-1) and $\Delta p h r$ (DP-1) cells were irradiated with UV light $\left(1200 \mathrm{~J} / \mathrm{m}^{2}\right)$ and cultivated in XTU liquid medium under light or dark conditions for viability testing. (a) SK-1. (b) DP-1. Open symbols: light conditions; closed symbols: dark conditions; solid lines, without UV irradiation; dotted lines: with UV irradiation. Error bars represent the standard deviation of two independent experiments. 


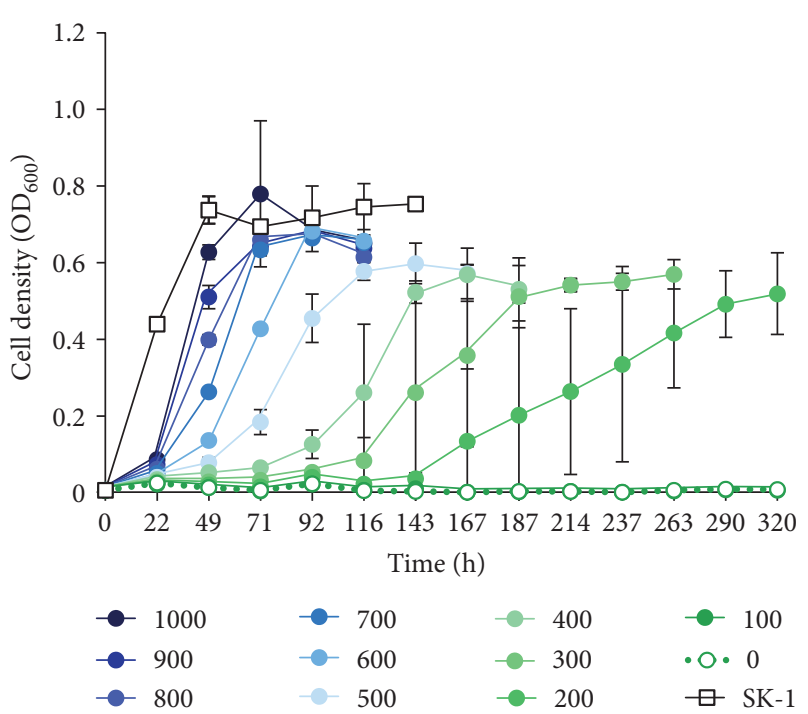

FIGURE 7: Growth curve of the $\operatorname{argD}$ deletion mutant SK-5. Wt (SK-1) and $\triangle \operatorname{argD}(\mathrm{SK}-5)$ were cultivated in XTU liquid medium with or without agmatine at $75^{\circ} \mathrm{C}$ with shaking. Closed circles: SK-5 with agmatine $(100-1000 \mu \mathrm{g} / \mathrm{mL})$; open circles: SK-5 without agmatine; open squares: SK-1 without agmatine. Error bars represent the standard deviation from three independent experiments.

$\triangle \arg D$ in-frame deletion mutant confirmed by sequencing, designated $S$. acidocaldarius strain SK-5, was characterized for phenotypic analysis.

3.6. Characterization of the argD Deletion Mutant SK-5. The growth of the $\operatorname{argD}$-deficient strain SK-5 ( $\triangle$ pyrE $\Delta$ suaI $\triangle \arg D$ ) was studied using XTU liquid culture in the presence or absence of agmatine (Figure 7). When SK-5 was cultivated in the presence of $1 \mathrm{mg} / \mathrm{mL}$ agmatine, growth was slightly retarded when compared with that of the host strain in the absence of agmatine. Particularly, the slowed growth of SK-5 became more striking at lower concentrations of agmatine. In contrast, SK-5 was not grown with less than $100 \mu \mathrm{g} / \mathrm{mL}$ agmatine.

3.7. Construction of a Stringent-Positive Selection Marker System Based on Agmatine Selection in S. acidocaldarius. The agmatine selection system has been reported as a stringent-positive selection marker system in the hyperthermophilic archaea Pyrococcus furiosus and S. islandicus $[10,20]$; however, this system has not been developed in $S$. acidocaldarius. To establish a selection marker system based on complementation of the $\operatorname{argD}$ gene, a $S$. acidocaldarius-E. coli shuttle vector pSAV2-argD was constructed by replacing the $S$. solfataricus pyrEF marker genes of pSAV2 with the $S$. solfataricus argD gene (SSO0536) (Figure 8(a)).

Host strain SK-5 ( $\Delta$ pyrE $\Delta$ suaI $\Delta \operatorname{argD})$ cells harvested at early to midlog phase $\left(\mathrm{OD}_{600}=0.308\right)$ were transformed with $8 \mathrm{ng}$ of plasmid DNA $(1 \mu \mathrm{L})$ by electroporation $(15 \mathrm{kV} / \mathrm{cm}$, $9 \mathrm{~ms}$ ) and spread on XTU plates (regeneration in recovery buffer was not conducted). Next, a previously published host-vector system based on complementation of the pyrE gene, SK-1 ( $\Delta p y r E \Delta s u a I)$, and plasmid vector pSAV2 [8] was analyzed under the same transformation conditions, except that competent cells were harvested at midlog phase $\left(\mathrm{OD}_{600}=0.420\right)$ and transformants were cultivated on XT plates. When SK-5 was transformed with pSAV2-argD, approximately $1.3 \times 10^{2} \pm 3.8 \times 10$ colonies grew with a transformation efficiency of $1.6 \times 10^{4} \pm 4.7 \times 10^{3}$ colonies $/ \mu \mathrm{g}$ DNA (Figure $8(\mathrm{~b})$ ). This result was similar (slightly lower) to the transformation efficiency of SK-1. Approximately $3.2 \times 10^{2} \pm 9.8 \times 10$ colonies grew with a transformation efficiency of $4.0 \times 10^{4} \pm 1.2 \times 10^{3}$ colonies/ $\mu$ g DNA. In addition, no colonies were formed in the control experiments with either selection system (without electroporation and plasmid vector) (Figure $8(\mathrm{~b})$ ).

\section{Discussion}

The goal of the present study was to establish a multiple gene knockout system with PCR tailing in the thermoacidophilic crenarchaeon $S$. acidocaldarius. For this, we first optimized the transformation protocol by characterizing the effects of transformation conditions on transformation efficiency. Next, we successfully developed a multiple gene knockout system with one-step PCR (MONSTER) by combining marker recycling with PCR tailing. This technique allows for the simple one-step construction of an unmarked gene knockout cassette and isolation of targeted gene deletion mutants. Unmarked gene deletion methodologies have been troublesome for genetic studies of other recombinogenic hyperthermophilic archaea. Although the development of PCR-tailing methods is possible for hyperthermophilic archaea, the potential for multiple gene knockout systems is limited due to the limited selectable marker systems. Thus, the MONSTER may be a speedy and powerful genetic tool for other recombinogenic hyperthermophilic archaea. In addition, we also constructed a stringent selectable marker system using agmatine, which provides the basis for further genetic manipulation in $S$. acidocaldarius.

Our results indicated that the main factors affecting transformation (homologous recombination) efficiency via double-crossover events were DNA topology, recovery conditions after electroporation, and flanking region length. In addition, the plating methods and the growth phase of competent cells were also important for optimizing transformation. In contrast, $\mathrm{CaCl}_{2}$ treatment and $\mathrm{DNA}$ volume did not affect transformation efficiency in this study.

The effects of DNA form on homologous recombination were reported in Sulfolobus species [2, 13]. Our results support a previous report that the transformation efficiency using linear DNA was higher than that of circular DNA $[2,13]$.

To develop a gene manipulation system based on PCR tailing, we focused on the possibility of sufficient homologous recombination via double-crossover events with very short homologous regions. The effects of flanking region length on homologous recombination efficiency in S. acidocaldarius were previously reported by Kurosawa and Grogan [13], and our data support their findings (Figure 3). The PCR-tailing technique was also previously established [1]. In contrast, our study is the first to report that sufficient transformation 


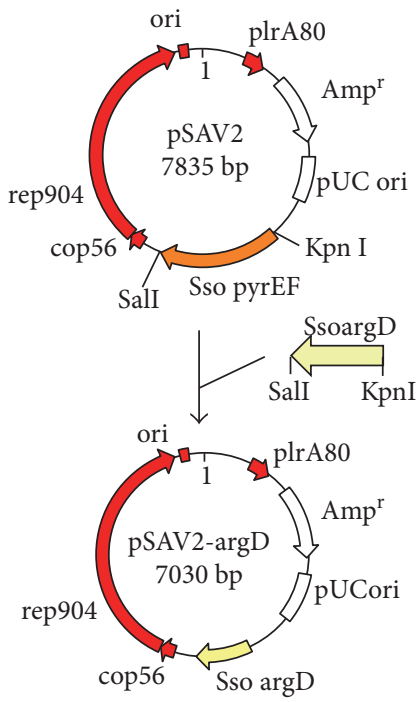

(a)

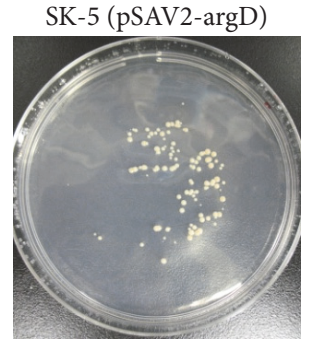

SK-1 (pSAV2)

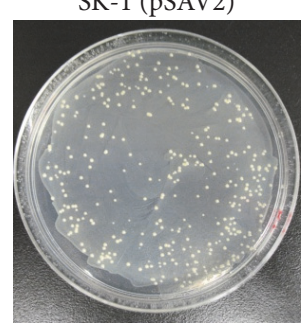

(b)

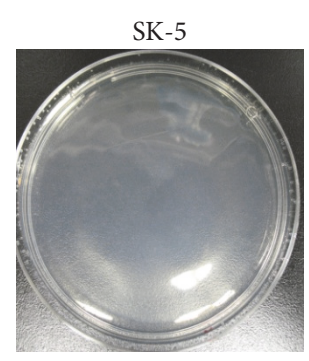

SK-1

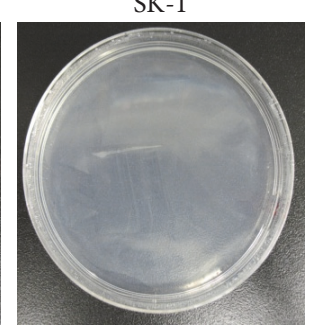

b)

FIGURE 8: Development of a transformation system based on agmatine selection for S. acidocaldarius. (a) Construction of pSAV2-argD. The $S$. solfataricus pyrEF operon was replaced by a $0.6 \mathrm{~kb}$ S. solfataricus argD marker. The resulting vector was named pSAV2-argD. (b) Transformation of the $\operatorname{argD}$ deletion mutant SK-5 with pSAV2-argD. Plating of SK-5 ( $\triangle$ pyrE $\Delta s u a I \Delta a r g D)$ transformed with $8 \mathrm{ng}$ of plasmid DNA of pSAV2-argD (SK-5 [pSAV2-argD]) on an XTU plate at $75^{\circ} \mathrm{C}$ for 10 days and SK-1 ( $\left.\triangle p y r E \Delta s u a I\right)$ transformed with $8 \mathrm{ng}$ of plasmid DNA of pSAV2 (SK-1 [pSAV2]) on an XT plate at $75^{\circ} \mathrm{C}$ for 7 days are shown. Controls (SK-1 and SK-5) included competent cells without plasmid DNA and electroporation.

efficiency for gene manipulation was demonstrated even with very short $(30-50 \mathrm{bp})$ flanking homologous arms. When 40 bp homologous arms were attached, the transformation efficiency using our protocol $(20 \pm 7$ colonies/ $\mu \mathrm{g})$ was slightly higher than that of the recombinogenic $P$. furiosus strain COM1 (6 colonies/ $\mu \mathrm{g}$ ) reported by Farkas et al. [21] (Figure 3). To our knowledge, no similar observation has been reported in the literature.

Homologous recombination (via double-crossover events) efficiencies using linear DNA have been reported in three hyperthermophilic archaea: Thermococcus kodakarensis KOD1, $10^{2}$ colonies/ $\mu$ g linear DNA containing $1 \mathrm{~kb}$ flanking regions [22]; $P$. furiosus COM1 (parent strain DSM 3638), $2.9 \times 10^{3}$ colonies/ $\mu$ g linear DNA containing $1 \mathrm{~kb}$ flanking regions [21]; S. islandicus M.16.4, 20-30 colonies/ $\mu$ g linearized DNA (pC-SsoargD) containing 755 and $671 \mathrm{bp}$ flanking regions [10] and 10-50 colonies/ $\mu \mathrm{g}$ linearized DNA (pMID-apt) containing 703 and $617 \mathrm{bp}$ flanking regions [23]; and S. islandicus REY15A, 10-200 colonies/ug linearized DNA (pKL2) containing $1.5 \mathrm{~kb}$ flanking regions [2]. The homologous recombination efficiency reported in our current study $\left(10^{2}-10^{3}\right.$ colonies/ $\mu$ g DNA) was higher than that of T. kodakarensis and S. islandicus and nearly identical to that of $P$. furiosus. However, these are not direct comparisons because the experimental conditions were different (e.g., size of the flanking regions and type of DNA construct). Notably, when transformed cells were regenerated under MBS buffer (Figure 2), the transformation efficiency $\left(2.8 \times 10^{4} \pm 6.9 \times 10^{3}\right.$ colonies $/ \mu \mathrm{g}$ DNA $)$ was similar to that of $S$. acidocaldarius transformed with plasmid vector $\left(1.6 \times 10^{4} \pm 4.7 \times 10^{3}\right.$ colonies/ $\mu \mathrm{g}$ pSAV2-argD and $4.0 \times 10^{4} \pm 1.2 \times 10^{3}$ colonies/ $\mu \mathrm{g}$ pSAV2) (Figure 8(b)). This high transformation efficiency will facilitate genetic studies and provide powerful advantages for the development of further genetic tools in this archaeon [24-26].

Improvement of electrotransformation efficiency by $\mathrm{CaCl}_{2}$ treatment in $S$. acidocaldarius was previously described (S. Suzuki and N. Kurosawa, presented at the Bioscience, Biotechnology, and Agrochemistry Convention, Japan, 27-30 March 2016); however, our study did not confirm this finding. Thus, further study is necessary to address this discrepancy.

Effective multiple gene knockout techniques have been developed in Sulfolobus [2-4]. However, the cloning steps of two to four fragments for construction of knockout vectors are required for these genetic tools. In addition, the screening of positive clones that contain the correct construct must be randomly selected during subcloning because $\mathrm{X}$-gal selection cannot be utilized. In contrast, PCR tailing is a highthroughput gene knockout technique [27]. However, the possibility of using this method for multiple gene knockout is limited in S. acidocaldarius because marker genes are lacking [1]. We developed the MONSTER by combining the multiple gene knockout technique with PCR tailing in S. acidocaldarius. The main advantage of the MONSTER compared with published unmarked gene deletion methodologies [2-4] is the very simple construction of multiple gene knockout cassettes without any plasmid construction. The usefulness of this technique was proven by unmarked gene knockout of the $p h r$ and $\arg D$ genes. Another advantage of the MONSTER is that multiple unmarked gene knockout cassettes can also be simultaneously amplified under the same PCR conditions because the sequences of MONSTER primers that anneal with the dual (pyrE-lacS) marker genes are identical, 
even though the attached flanking regions of the target genes are different. Therefore, MONSTER is a high-throughput method compared with the widely used methods in Sulfolobus [2-4]. Notably, the purification of intermediate transformants (Int strain) was very important for pop-out selection (Figures 4(c) and 5(c)). Thus, this study provides an alternative and versatile strategy for the genetic manipulation of $S$. acidocaldarius with several advantages.

To establish the MONSTER in other hyperthermophilic archaea, dual marker genes are required for counterselection and screening (Figures 4(c) and 5(c)). In addition, recombinogenic host strains that allow for homologous recombination using very short flanking homologous regions is likely required.

A uracil-based selection system (pyrE-, pyrF-, or pyrEF-deficient strains and marker genes) cannot efficiently estimate transformation efficiency in hyperthermophilic archaea due to the interference caused by background growth of the pyrEF-deficient strain on solid medium [10]. In contrast, an agmatine selection system is a powerful genetic marker due to the lack of background colony growth on plates (Figure 8(b)) [10]. Therefore, the genetic marker system developed in this study will allow versatile genetic manipulation in S. acidocaldarius. Notably, a higher concentration of agmatine was required for cultivation of the $S$. acidocaldarius $\operatorname{argD-deficient}$ strain when compared with other hyperthermophiles [10, 20, 23, 28].

We previously reported that no background colonies appeared in the host-vector system (especially the SK-1 strain) using uracil selection for a 7-day cultivation [8]. This advantage was confirmed with our stringent positive marker system based on agmatine selection (Figure 8(b)).

Additionally, we constructed the DNA photolyasedeficient strain DP-1 as a genetic host strain that does not require dark conditions for the functional genetic analysis of candidate genes involved in the UV response [29-31].

\section{Conclusion}

We combined marker recycling (pop-out recombination) with PCR tailing to develop a multiple gene knockout system with one-step PCR. In addition to the widely used multiple gene knockout techniques in S. acidocaldarius, this study describes an alternative strategy that enables the very simple construction of multiple gene knockout cassettes. Indeed, we believe our techniques will contribute to the genetic study of this archaeon.

\section{Conflicts of Interest}

The authors declare that they have no conflicts of interest.

\section{References}

[1] C. J. Sakofsky, L. A. Runck, and D. W. Grogan, "Sulfolobus mutants, generated via PCR products, which lack putative enzymes of UV photoproduct repair," Archaea, vol. 2011, Article ID 864015, 12 pages, 2011.
[2] L. Deng, H. Zhu, Z. Chen, Y. X. Liang, and Q. She, "Unmarked gene deletion and host-vector system for the hyperthermophilic crenarchaeon Sulfolobus islandicus," Extremophiles, vol. 13, no. 735, pp. 735-746, 2009.

[3] C. Zhang, L. Guo, L. Deng et al., "Revealing the essentiality of multiple archaeal pcna genes using a mutant propagation assay based on an improved knockout method," Microbiology, vol. 156, no. 11, pp. 3386-3397, 2010.

[4] M. Wagner, M. V. Wolferen, A. Wagner et al., "Versatile genetic tool box for the crenarchaeote Sulfolobus acidocaldarius," Frontiers in Microbiology, vol. 3, no. 214, 2012.

[5] Q. She, C. Zhang, L. Deng, N. Peng, Z. Chen, and Y. X. Liang, "Genetic analyses in the hyperthermophilic archaeon Sulfolobus islandicus," Biochemical Society Transactions, vol. 37, no. 1, pp. 92-96, 2009.

[6] M. Wagner, S. Berkner, M. Ajon, A. J. M. Driessen, G. Lipps, and S. V. Albers, "Expanding and understanding the genetic toolbox of the hyperthermophilic genus Sulfolobus," Biochemical Society Transactions, vol. 37, no. 1, pp. 97-101, 2009.

[7] C. Zhang, B. Tian, S. Li et al., "Genetic manipulation in Sulfolobus islandicus and functional analysis of DNA repair genes," Biochemical Society Transactions, vol. 41, no. 1, pp. 405-410, 2013.

[8] S. Suzuki and N. Kurosawa, "Disruption of the gene encoding restriction endonuclease SuaI and development of a hostvector system for the thermoacidophilic archaeon Sulfolobus acidocaldarius," Extremophiles, vol. 20, no. 2, pp. 139-148, 2016.

[9] D. W. Grogan, "Isolation of Sulfolobus acidocaldarius mutants," in Archaea: A Laboratory Manual, F. T. Robb, A. R. Place, K. R. Sowers, H. J. Schreier, S. DasSarma and E. M. Fleishmann, Eds., Cold Spring Harbor Laboratory, Cold Spring Harbor, NY, USA, 1996.

[10] C. Zhang, T. E. Cooper, D. J. Krause, and R. J. Whitaker, "Augmenting the genetic toolbox for Sulfolobus islandicus with a stringent positive selectable marker for agmatine prototrophy," Applied and Environmental Microbiology, vol. 79, no. 18, pp. 5539-5549, 2013.

[11] N. Kurosawa, Y. H. Itoh, T. Iwai et al., "Sulfurisphaera ohwakuensis gen. nov., sp. nov., a novel extremely thermophilic acidophile of the order Sulfolobales," International Journal of Systematic Bacteriology, vol. 48, no. 2, pp. 451-456, 1998.

[12] S. Berkner, D. Grogan, S. V. Albers, and G. Lipps, "Small multicopy, non-integrative shuttle vectors based on the plasmid pRN1 for Sulfolobus acidocaldarius and Sulfolobus solfataricus, model organisms of the (cren-)archaea," Nucleic Acids Research, vol. 35, no. 12, article e88, 2007.

[13] N. Kurosawa and D. W. Grogan, "Homologous recombination of exogenous DNA with the Sulfolobus acidocaldarius genome: properties and uses," FEMS Microbiology Letters, vol. 253, no. 1, pp. 141-149, 2005.

[14] T. D. Xie, L. Sun, and T. Y. Tsong, "Study of mechanisms of electric field-induced DNA transfection. I. DNA entry by surface binding and diffusion through membrane pores," Biophysical Journal, vol. 58, no. 1, pp. 13-19, 1990.

[15] T. D. Xie and T. Y. Tsong, "Study of mechanisms of electric field-induced DNA transfection. III. Electric parameters and other conditions for effective transfection," Biophysical Journal, vol. 63, no. 1, pp. 28-34, 1992.

[16] T. D. Xie, L. Sun, H. G. Zhao, J. A. Fuchs, and T. Y. Tsong, "Study of mechanisms of electric field-induced DNA 
transfection. IV. Effects of DNA topology on cell uptake and transfection efficiency," Biophysical Journal, vol. 63, no. 4, pp. 1026-1031, 1992.

[17] C. Schleper, K. Kubo, and W. Zillig, “The particle SSV1 from the extremely thermophilic archaeon Sulfolobus is a virus: demonstration of infectivity and of transfection with viral DNA," Proceedings of the National Academy of Sciences of the United States of America, vol. 89, no. 16, pp. 7645-7649, 1992.

[18] D. W. Grogan, "Understanding DNA repair in hyperthermophilic archaea: persistent gaps and other reactions to focus on the fork," Archaea, vol. 2015, Article ID 942605, 12 pages, 2015.

[19] T. N. Giles and D. E. Graham, "Crenarchaeal arginine decarboxylase evolved from an S-adenosylmethionine decarboxylase enzyme," Journal of Biological Chemistry, vol. 283, no. 38, pp. 25829-25838, 2008.

[20] R. C. Hopkins, J. Sun, F. E. J. Jenney, S. K. Chandrayan, P. M. McTernam, and M. W. W. Adams, "Homologous expression of a subcomplex of Pyrococcus furiosus hydrogenase that interacts with pyruvate ferredoxin oxidoreductase," PLoS One, vol. 6, no. 10, article e26569, 2011.

[21] J. Farkas, K. Stirrett, G. L. Lipscomb et al., "Recombinogenic properties of Pyrococcus furiosus strain COM1 enable rapid selection of targeted mutants," Applied and Environmental Microbiology, vol. 78, no. 13, pp. 4669-4676, 2012.

[22] T. Sato, T. Fukui, H. Atomi, and T. Imanaka, "Improved and versatile transformation system allowing multiple genetic manipulations of the hyperthermophilic archaeon Thermococcus kodakaraensis," Applied and Environmental Microbiology, vol. 71, no. 7, pp. 3889-3899, 2005.

[23] C. Zhang, Q. She, H. Bi, and R. J. Whitaker, "The apt/6methylpurine counterselection system and its applications in genetic studies of the hyperthermophilic archaeon Sulfolobus islandicus," Applied and Environmental Microbiology, vol. 82, no. 10, pp. 3070-3081, 2016.

[24] J. F. Carr, S. T. Gregory, and A. E. Dahlberg, "Transposon mutagenesis of the extremely thermophilic bacterium Thermus thermophiles HB27," Extremophiles, vol. 19, no. 1, pp. 221-228, 2015.

[25] Y. Li, S. Pan, Y. Zhang et al., "Harnessing type I and type III CRISPR-Cas systems for genome editing," Nucleic Acids Research, vol. 44, no. 4, p. 34e, 2015.

[26] N. Guschinskaya, R. Brunel, M. Tourte et al., "Random mutagenesis of the hyperthermophilic archaeon Pyrococcus furiosus using in vitro mariner transposition and natural transformation,” Scientific Reports, vol. 6, article 36711, 2016.

[27] K. A. Datsenko and B. L. Wanner, "One-step inactivation of chromosomal genes in Escherichia coli K-12 using PCR products," Proceedings of the National Academy of Sciences of the United States of America, vol. 97, no. 12, pp. 6640-6645, 2000.

[28] W. Fukuda, N. Morimoto, T. Imanaka, and S. Fujiwara, "Agmatine is essential for the cell growth of Thermococcus kodakaraensis," FEMS Microbiology Letters, vol. 287, no. 1, pp. 113-120, 2008.

[29] S. Fröls, P. M. K. Gordon, M. A. Panlilio et al., "Response of the hyperthermophilic archaeon Sulfolobus solfataricus to UV damage," Journal of Bacteriology, vol. 189, no. 23, pp. 8708-8718, 2007.

[30] D. Götz, S. Paytubi, S. Munro, M. Lundgren, R. Bernander, and M. F. White, "Responses of hyperthermophilic crenarchaea to UV irradiation," Genome Biology, vol. 8, no. 10, article R220, 2007.

[31] S. Fröls, M. F. White, and C. Schleper, "Reactions to UV damage in the model archaeon Sulfolobus solfataricus," Biochemical Society Transactions, vol. 37, no. 1, pp. 36-41, 2009.

[32] M. S. Reilly and D. W. Grogan, "Characterization of intragenic recombination in a hyperthermophilic archaeon via conjugational DNA exchange," Journal of Bacteriology, vol. 183, no. 9, pp. 2943-2946, 2001. 

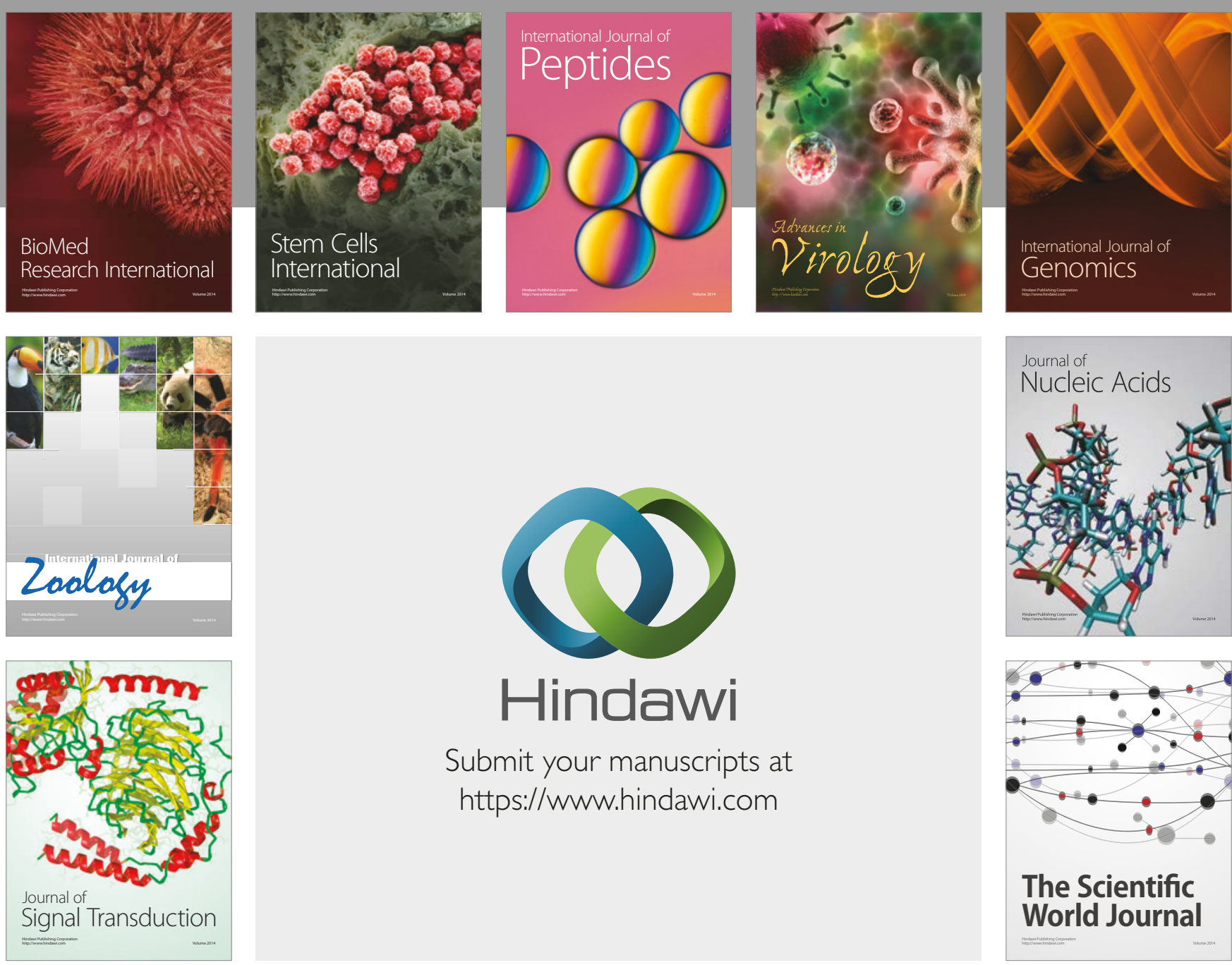

Submit your manuscripts at

https://www.hindawi.com
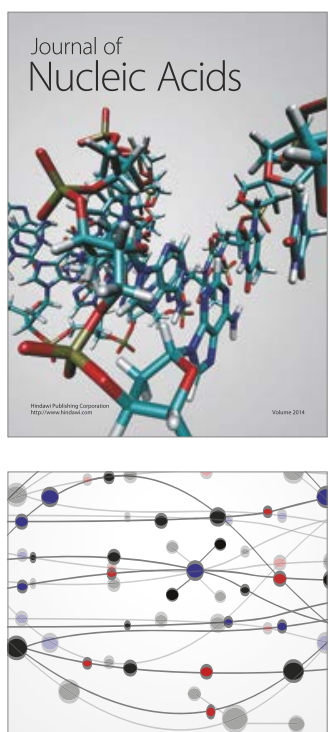

The Scientific World Journal

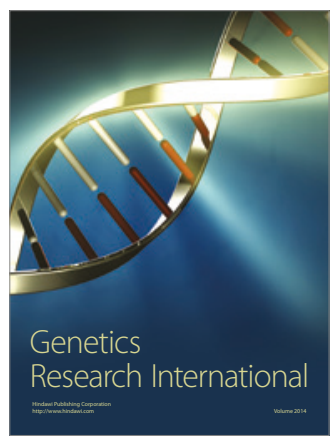

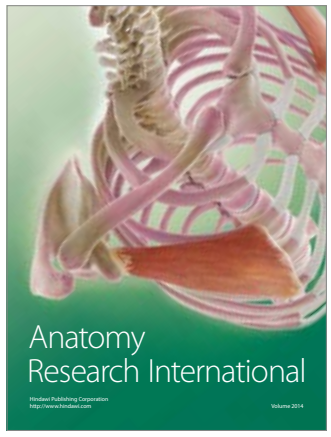

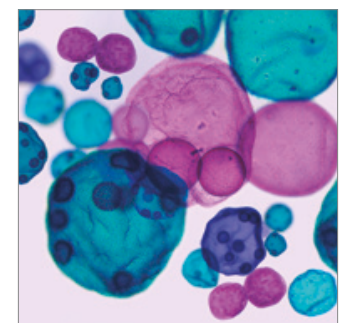

International Journal of Microbiology
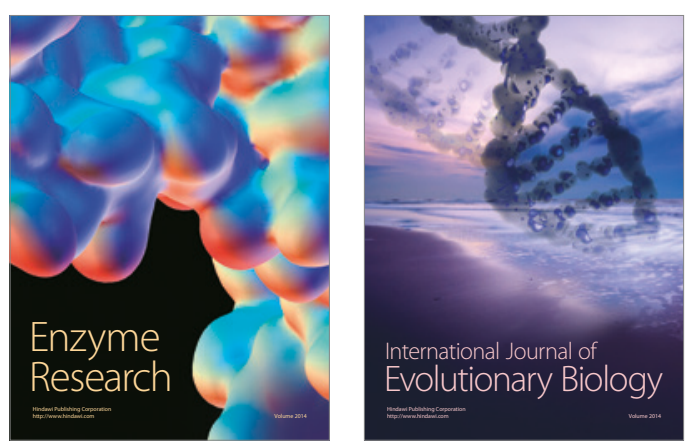
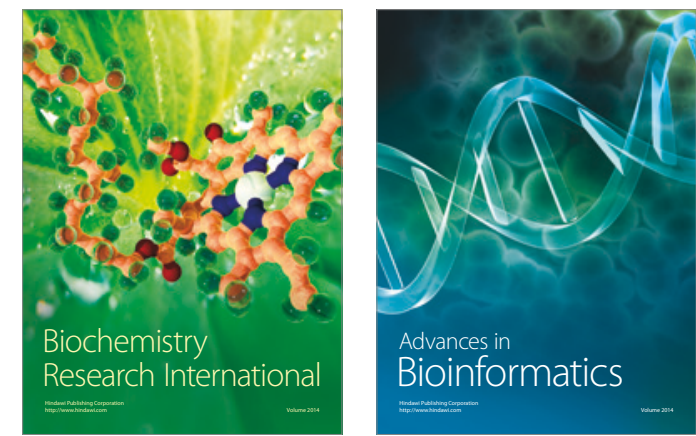

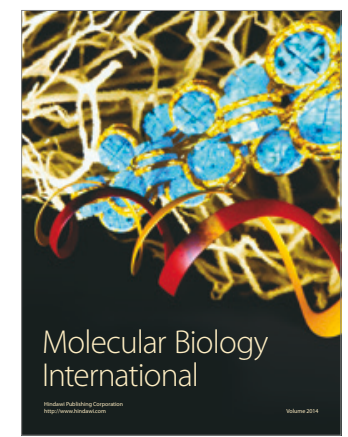

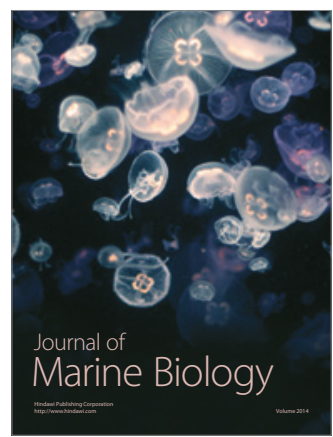

